\title{
INTRAUTERINE GROWTH CHARTS FOR FETAL BIPARIETAL DIAMETER BETWEEN 12 AND 40 WEEKS OF PREGNANCY AND ITS CORRELATION WITH GESTATIONAL AGE
}

\author{
SHRIPAD HEBBAR*, TRACY KHURAIJAM \\ Department of Obstetrics and Gynaecology, Kasturba Medical College, Manipal, Karnataka, India. Email: shripad.hebbar@manipal.edu
} Received: 12 December 2017, Revised and Accepted: 15 January 2018

\section{ABSTRACT}

Objective: The objective of this study is to derive intrauterine growth charts for fetal biparietal diameter (BPD) at weekly intervals between 12 and 40 weeks of gestation and to correlate BPD with the gestational age (GA).

Methods: In a prospective observational study, a total of 100 women underwent periodic ultrasound examination between 12 and 40 weeks of gestation. Using Microsoft Excel trend line feature, polynomial regression was performed for each of this patient and weekly BPD values were extrapolated. For each week of gestation, we obtained 100 data points, and these were entered into SPSS software to obtain means, standard deviations (SD), and percentile charts for BPD. Relationship between GA and BPD was also established using curvilinear regression. Z scores were used to compare the findings of the present study with Indian, Asian, and non-Asian regions. The incremental growth of BPD per week was also established for the same GA range.

Results: The mean \pm SD of BPD value at 12 weeks was $20.4 \pm 0.94 \mathrm{~mm}$, which gradually increased to $92.5 \pm 2.89 \mathrm{~mm}$ at full term. There was a strong relationship between BPD and GA as indicated by polynomial regression analysis. As gestation advanced, BPD growth rate slowed down from 3.5 mm from mid-pregnancy to around $1 \mathrm{~mm}$ at term. Our BPD charts resembled closely Chinese and US growth charts.

Conclusion: There was a good mathematical relationship between fetal BPD and GA. The BPD charts and percentile tables derived from the present study help to establish customized growth charts for the local population.

Keywords: Biparietal diameter, Gestational age, Intrauterine growth chart.

(C) 2018 The Authors. Published by Innovare Academic Sciences Pvt Ltd. This is an open access article under the CC BY license (http://creativecommons. org/licenses/by/4. 0/) DOI: http://dx.doi.org/10.22159/ajpcr.2018.v11i4.24090

\section{INTRODUCTION}

It is a standard practice to estimate the duration of pregnancy using patient's recalled $1^{\text {st }}$ day of last menstrual period (LMP) [1]. LMP itself is subjected to poor recall and is influenced by several factors such as irregular cycles, lactational amenorrhea, usage of oral contraceptive pills, and implantation bleeding [2]. In the modern era, measurement of fetal biometric parameters can be helpful in the determination of gestational age (GA) and the error can be minimized when ultrasound is performed in early in pregnancy. Biparietal diameter (BPD) is one such parameter which has been used to estimate GA for the past four decades [3]. Knowledge of correct GA is of utmost importance in present-day obstetric practice, as many interventions are based on accurate dating, such as steroid administration, preventing preterm and post-term births, planning timing of delivery, and preventing untimely induction of labor [4].

BPD is not only used for calculation of GA but also it can diagnose aberrant fetal growth and many central nervous system anomalies can also be detected while measuring BPD in its correct plane [5]. There are two types of BPD growth abnormalities: First one is slow growth profile and the second is late trimester flattening [6]. However, this requires comparison to standard BPD growth chart which has been previously studied and customized for the local population.

In India, there are few publications which focus on the relationship between GA and BPD and vice versa. There is a wide variation in BPD measurements in different places, as it is influenced by maternal nutritional status, demographic pattern, and racial differences. BPD of one population may either underestimate or overestimate GA, and hence, it is very important to have BPD charts customized for local population [7]. In this study, we have correlated bidirectionally GA and
BPD from $12^{\text {th }}$ week of gestation to 40 weeks of pregnancy in South Indian population.

\section{METHODS}

This was a prospective observational study conducted at a tertiary care hospital which is attached to medical college between August 2014 and August 2016 in the Department of Obstetrics and Gynaecology, KMC, Manipal, which is a tertiary care center. The study was approved by the Institutional Ethics Committee (ref no: IEC: 465/2014) and all participating women gave informed consent. We included only those women who had singleton uncomplicated pregnancies with BPD measurement values between 12 and 40 weeks and who delivered at term. Their reliability of LMP was correlated with first trimester dating scan using crown rump length (CRL) measurements. If they found to have fetal growth restriction, medical complications such as congenital anomaly, gestational diabetes, pre-eclampsia, and intrauterine fetal demise during the follow-up, they were excluded from the study. The most important criterion was the availability of patients through the entire period between 12 and 40 weeks.

We used Philips HD 11XE machine for BPD measurements using 3.5 $\mathrm{MHz}$ curvilinear probe. We first determined the lie of the fetus and spine curvature. The transducer was turned at right angles to the fetal spine and by gradual sliding motion; transverse section of the fetal head was obtained. The correct plane for BPD measurement was defined as transthalamic plane, which showed oval-shaped head circumference, midline falx, and septum cavum pellucidum dividing the brain into two equal hemispheres and thalamic structures slightly posteriorly [8].

Our ultimate objective was to obtain at least 5-6 scan results between 12 and 40 weeks to plot growth charts. Rather than calling them on 
specified GA, we recorded BPD values whenever they were called for routine antenatal visits. All the patients had an initial scan at 12-14 weeks (early anomaly scan), 18-20 weeks (targeted scan), 2832 weeks (growth scan), and between 32 and 40 weeks (at least 2-3 interval scans).

We used Microsoft Excel graph feature to plot the growth points using X-axis for GA and Y-axis for BPD measurements. The data points were further smoothened using Excel trend line feature, which also gave polynomial equation between GA and BPD. Having obtained the regression equation, we further extrapolated BPD values at weekly intervals from 12 to 40 weeks of gestation. The details of this procedure can be obtained by author's publication on Microsoft Excel non-linear curve fitting [9].

\section{Sample size determination}

In a study by Lai and Yeo from Singapore, BPD (in $\mathrm{mm}$ ) at term was found to be $93.09 \pm 3.1$ [10]. Using sample size equation " $n=2(z \alpha+z \beta)^{2} \sigma^{2} / \Delta \mu^{2}$," we found that sample size of 37 would be adequate. We recruited 148 patients for the study keeping in mind (dropout rate due to onset of pregnancy complications where in early delivery would have been required, patient who changed the institution for their delivery). The final sample of study size was 100 which was 3 times more than the actual sample size required, thereby increasing the power of the study.

\section{Statistical analysis}

We obtained BPD values for all 100 patients between 12 and 40 weeks of gestation at weekly interval by the method which has been already discussed, and this information was entered into SPSS version 16 statistical package. Descriptive analysis was used to find the mean and standard deviation (SD) at specified intervals. Centile charts were also prepared using inbuilt tool in the same package. We used Z statistics to compare our values with the published values across various GAs.

- Z-scores were calculated using the formula.

- $\mathrm{Z}$-score $=\left(\mathrm{X}^{\mathrm{GA}}-\mathrm{M}^{\mathrm{GA}}\right) / \mathrm{SD}^{\mathrm{GA}}$, where in

- $\mathrm{X}^{\mathrm{GA}}$ - mean BPD from reference population at a specified GA.

- $\quad \mathrm{M}^{\mathrm{GA}}$ - mean $\mathrm{BPD}$ from study population for the same GA.

- $\mathrm{SD}^{\mathrm{GA}}-\mathrm{SD}$ associated with the mean value at this GA in the current study.

\section{RESULTS}

We had initially recruited 148 pregnant women for the current study. Of them, 14 patients developed gestational diabetes, 13 had hypertension, 8 went into preterm labor, 6 women defaulted for regular check-ups, and 7 patients changed the institution. The BPD data were collected for remaining 100 pregnant women, and detailed descriptive analysis was done using SPSS package and Microsoft excel program as detailed in materials and methods section.

Table 1 shows mean, SD, and percentile values for BPD obtained in our study. The mean \pm SD of BPD value at 12 weeks was $20.4 \pm 0.94 \mathrm{~mm}$, which gradually increased to $92.5 \pm 2.89 \mathrm{~mm}$ at full term. The relationship between BPD and GA was established by the following polynomial regression equation.

$\mathrm{BPD}=\left(-6.64414+[1.280198 \times \mathrm{GA}]+0.103147 \times\left[\mathrm{GA}^{2}\right]-0.0018296 \times \mathrm{GA}^{3}\right)$

Fig. 1 shows that BPD percentiles for GA range between 12 and 40 weeks at weekly intervals. This figure can be used for charting BPD values at a particular GA and this will help us identification of pregnancies affected by intrauterine growth restriction and macrosomic babies.

Table 2 summarizes GA in weeks for the corresponding BPD values in $\mathrm{mm}$ (from $20 \mathrm{~mm}$ to $95 \mathrm{~mm}$ ). The relationship between GA and BPD is explained by $4^{\text {th }}$ degree polynomial equation as follows:

$\mathrm{GA}=\left(\left[0.0000000706676825481 \times \mathrm{BPD}^{4}\right]+\left[0.0000499804240801 \times \mathrm{BPD}^{3}\right]-\right.$ $\left[0.00827813323368 \times \mathrm{BPD}^{2}\right]+[0.70632536575 \times \mathrm{BPD}]+$ 0.113912991506
Fig. 2 shows relationship between GA and BPD graphically. From Table 2 and Fig. 2, one can estimate the gestational age for the given BPD value.

Fig. 3 shows BPD growth velocity in mm per week of gestation. It can be seen that as the gestation advances, BPD growth rate slows down (from

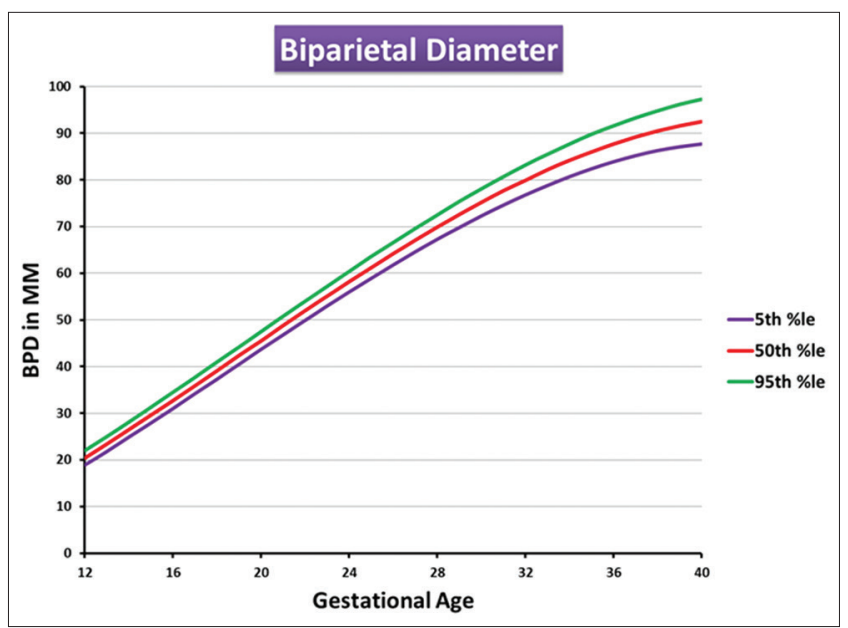

Fig. 1: Centile values for biparietal diameter at various gestational ages

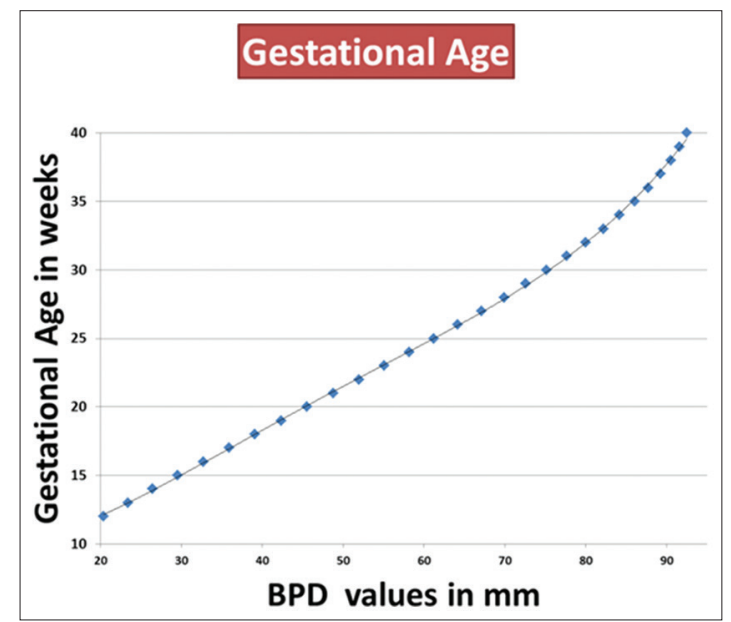

Fig. 2: Graphical relationship between gestational age and biparietal diameter

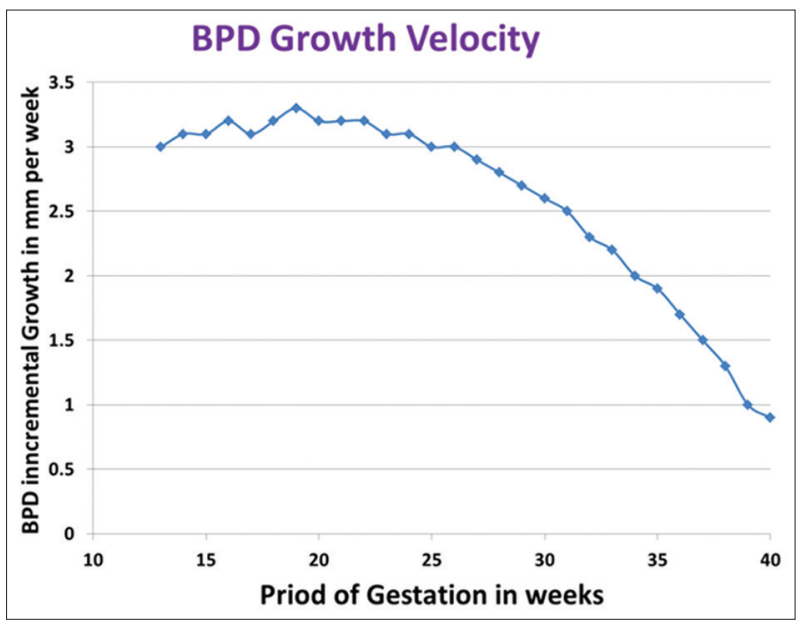

Fig. 3: Biparietal diameter growth velocity across various gestational ages 
Table 1: Descriptive statistics of BPD parameters between 12 and 40 weeks

\begin{tabular}{|c|c|c|c|c|c|c|c|c|}
\hline GA & Mean \pm SD & $5^{\text {th }} \%$ le & $10^{\text {th }} \%$ le & $25^{\text {th }} \%$ le & $50^{\text {th }} \%$ le & $75^{\text {th }} \%$ le & $90^{\text {th }} \%$ le & $95^{\text {th }} \%$ le \\
\hline 12 & $20.4 \pm 0.94$ & 18.9 & 19.2 & 19.8 & 20.4 & 21 & 21.6 & 22 \\
\hline 13 & $23.4 \pm 0.96$ & 21.8 & 22.2 & 22.8 & 23.4 & 24.1 & 24.6 & 25 \\
\hline 14 & $26.5 \pm 0.99$ & 24.9 & 25.2 & 25.8 & 26.5 & 27.1 & 27.7 & 28.1 \\
\hline 15 & $29.6 \pm 1.01$ & 27.9 & 28.3 & 28.9 & 29.6 & 30.3 & 30.9 & 31.3 \\
\hline 16 & $32.8 \pm 1.04$ & 31 & 31.4 & 32.1 & 32.7 & 33.5 & 34.1 & 34.5 \\
\hline 17 & $35.9 \pm 1.07$ & 34.2 & 34.6 & 35.2 & 35.9 & 36.7 & 37.3 & 37.7 \\
\hline 18 & $39.1 \pm 1.1$ & 37.3 & 37.7 & 38.4 & 39.1 & 39.9 & 40.6 & 41 \\
\hline 20 & $45.6 \pm 1.17$ & 43.7 & 44.1 & 44.8 & 45.5 & 46.4 & 47.1 & 47.5 \\
\hline 21 & $48.8 \pm 1.21$ & 46.8 & 47.2 & 48 & 48.8 & 49.6 & 50.3 & 50.8 \\
\hline 22 & $52 \pm 1.25$ & 49.9 & 50.4 & 51.1 & 52 & 52.8 & 53.6 & 54 \\
\hline 23 & $55.1 \pm 1.3$ & 53 & 53.4 & 54.2 & 55.1 & 56 & 56.8 & 57.2 \\
\hline 24 & $58.2 \pm 1.35$ & 56 & 56.5 & 57.3 & 58.2 & 59.1 & 59.9 & 60.4 \\
\hline 25 & $61.2 \pm 1.41$ & 58.9 & 59.4 & 60.3 & 61.2 & 62.2 & 63 & 63.6 \\
\hline 26 & $64.2 \pm 1.47$ & 61.8 & 62.3 & 63.2 & 64.2 & 65.2 & 66.1 & 66.6 \\
\hline 27 & $67.1 \pm 1.53$ & 64.6 & 65.1 & 66.1 & 67.1 & 68.1 & 69.1 & 69.6 \\
\hline 30 & $75.2 \pm 1.76$ & 72.3 & 72.9 & 74 & 75.2 & 76.4 & 77.4 & 78.1 \\
\hline 31 & $77.7 \pm 1.84$ & 74.6 & 75.3 & 76.4 & 77.7 & 78.9 & 80 & 80.7 \\
\hline 32 & $80 \pm 1.93$ & 76.8 & 77.5 & 78.7 & 79.9 & 81.3 & 82.5 & 83.2 \\
\hline 33 & $82.2 \pm 2.03$ & 78.8 & 79.6 & 80.8 & 82.2 & 83.5 & 84.8 & 85.5 \\
\hline 34 & $84.2 \pm 2.13$ & 80.7 & 81.5 & 82.8 & 84.2 & 85.6 & 86.9 & 87.7 \\
\hline 35 & $86.1 \pm 2.24$ & 82.4 & 83.2 & 84.6 & 86 & 87.6 & 88.9 & 89.8 \\
\hline 36 & $87.8 \pm 2.36$ & 83.9 & 84.7 & 86.2 & 87.7 & 89.3 & 90.8 & 91.6 \\
\hline 37 & $89.3 \pm 2.48$ & 85.2 & 86.1 & 87.6 & 89.2 & 90.9 & 92.4 & 93.3 \\
\hline 38 & $90.6 \pm 2.61$ & 86.3 & 87.2 & 88.8 & 90.5 & 92.3 & 93.9 & 94.8 \\
\hline 39 & $91.6 \pm 2.75$ & 87.1 & 88.1 & 89.8 & 91.6 & 93.5 & 95.2 & 96.2 \\
\hline 40 & $92.5 \pm 2.89$ & 87.7 & 88.8 & 90.6 & 92.5 & 94.5 & 96.2 & 97.3 \\
\hline
\end{tabular}

SD: Standard deviation, BPD: Biparietal diameter, GA: Gestational age

Table 2: Calculation of GA (in weeks and days) based on BPD measurements in mm

\begin{tabular}{|c|c|c|c|c|c|c|c|}
\hline BPD (mm) & GA (W and D) & BPD (mm) & GA (W and D) & BPD (mm) & GA (W and D) & BPD (mm) & GA (W and D) \\
\hline 20 & 11W2D & 39 & 18W1D & 58 & 23W5D & 77 & 30W5D \\
\hline 21 & 11W5D & 40 & 18W4D & 59 & 24W1D & 78 & 31W1D \\
\hline 22 & 12W1D & 41 & 18W6D & 60 & 24W3D & 79 & 31W4D \\
\hline 23 & 12W4D & 42 & 19W1D & 61 & 24W5D & 80 & $32 W 1 D$ \\
\hline 24 & 13W0D & 43 & 19W3D & 62 & 25W0D & 81 & $32 W 4 D$ \\
\hline 25 & 13W3D & 44 & 19W5D & 63 & 25W3D & 82 & 33W1D \\
\hline 26 & 13W6D & 45 & 19W7D & 64 & 25W5D & 83 & $33 W 4 D$ \\
\hline 27 & 14W1D & 46 & 20W2D & 65 & 26W0D & 84 & 34W1D \\
\hline 28 & 14W4D & 47 & 20W4D & 66 & 26W3D & 85 & $34 \mathrm{~W} 5 \mathrm{D}$ \\
\hline 29 & 14W6D & 48 & 20W6D & 67 & 26W5D & 86 & 35W2D \\
\hline 30 & 15W2D & 49 & 21W1D & 68 & 27W1D & 87 & 35W6D \\
\hline 31 & 15W4D & 50 & 21W3D & 69 & 27W3D & 88 & 36W3D \\
\hline 32 & 15W7D & 51 & 21W5D & 70 & 27W6D & 89 & 37W0D \\
\hline 33 & 16W2D & 52 & 22W0D & 71 & 28W2D & 90 & $37 W 5 D$ \\
\hline 34 & 16W4D & 53 & 22W2D & 72 & 28W4D & 91 & 38W2D \\
\hline 35 & 16W7D & 54 & 22W4D & 73 & 29W0D & 92 & 39W0D \\
\hline 36 & 17W2D & 55 & 22W6D & 74 & 29W3D & 93 & 39W5D \\
\hline 37 & 17W4D & 56 & 23W1D & 75 & 29W6D & 94 & 40W3D \\
\hline 38 & 17W6D & 57 & 23W3D & 76 & 30W2D & 95 & 41W1D \\
\hline
\end{tabular}

BPD: Biparietal diameter, GA: Gestational age

$3.5 \mathrm{~mm}$ from mid-pregnancy to around $1 \mathrm{~mm}$ at term). BPD-based GA calculation in third trimester is prone to error because of its slow growth late gestation.

\section{DISCUSSION}

The ultrasound measurement of BPD was first described by Donald and Brown in 1967 [11]. Initially, "A" mode scan was used to obtain the BPD, but later Campbell described B mode scan for fetal head measurement [12]. Subsequently, Griffit and Henry showed that BPD can be imaged in real-time mode [13]. The best predictor of fetal age is CRL correlation, but its limitation is that it cannot be measured after 14 weeks of pregnancy. BPD is the next best fetal parameter to assess the GA after 12 weeks of gestation and it can be measured throughout the gestation, but only limitation is that as the trimester advances, its accuracy falls [14].

There is a wide variation in BPD values of South Indian fetuses compared to western standards. This is because fetal biometry is influenced by several factors such as maternal nutritional status, race, ethnicity, parental height, and even for that matter, the fetal sex [15]. Table 3 shows comparative analysis of BPD values in various Indian hall mark studies.

We compared our values with published values using $\mathrm{Z}$ score (also known as standard score). This helps us to find how close are published 
mean values of BPD compared to our mean values and fall within what range of SD as observed from our study. The method of obtaining $\mathrm{Z}$ score has been already explained in materials and method section. We can consider that published value is very close to our values if they fall within $1 \mathrm{SD}$. A positive $\mathrm{Z}$ score will mean that particular value is more than our value and vice versa, and if the score is negative, then they are lesser than our observations. A Z score toward zero implies that there are no differences in two studies.

Fig. 4 shows $\mathrm{Z}$ statistics for other Indian studies. We can conclude that Chennai and Gujarat studies (observations fall within $\pm 0.5 \mathrm{SD}$ ) are closed to our study. However, the Pune study showed significant differences in mean BPD value still 36weeks, but thereafter, BPD in all three studies came close to our study.

Table 4 shows a comparison of BPD values in the present study with other Asian population. The similarities and differences in the different studies have been analyzed and Fig. 5 shows the differences graphically. Although there were differences in the values in the initial part of pregnancy, it is well seen that all the studies showed comparable values in the second half of pregnancy. Of all the South Asian regions, observations from China were very close to the present study.

We also compared the results of our study with non-Asian countries (Table 5). Surprisingly by Z score analysis (Fig. 6), we found that our values did not differ much from the USA-based study. The BPD values from Netherland population appeared to be higher compared to our study, indicating that their fetuses had high growth profile.

The strength of the present study is that it provides a detailed GA wise percentile descriptive for BPD, calculation of GA for the known BPD, and also the incremental growth rate for BPD in different trimesters of pregnancy. The regression equations are also computed. The size of fetal head in terms of BPD will also throw light on cephalopelvic proportions which otherwise earlier was only relied on subjective clinical assessment or radiopelvimetry before the advent of ultrasound technology $[29,30]$

To summarize, there is a good mathematical relationship between fetal BPD and GA. We are of the opinion that the methodology used in the present study, percentile tables, and charts of BPD will serve as a good reference source and database for future studies in this field of research. The customized growth charts will also help us to monitor pregnancies complicated by pregnancy hypertension [31], maternal diabetes, hypothyroidism [32], and other medical disorders which influence the intrauterine fetal growth.

\section{CONCLUSION}

In the current obstetric practice, the accurate assessment of GA is of critical importance, especially in situations such as fetal growth restriction, postdated pregnancy, placenta previa, medical disorders complicating pregnancy such as pre-eclampsia, diabetes, and more so ever in management of pre-term labor. Ultrasound becomes handy in such conditions, as by measuring various fetal parameters, approximate

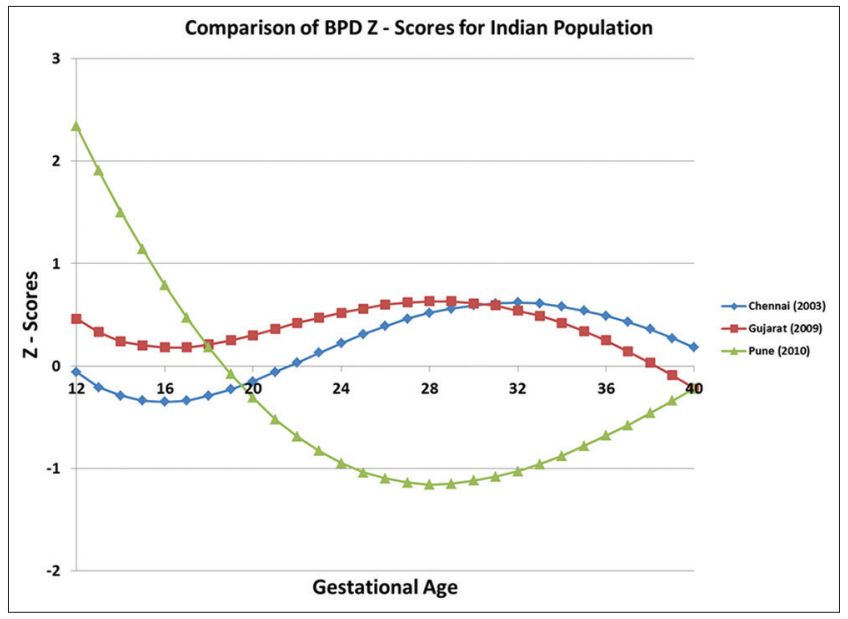

Fig. 4: Z score comparison with Indian studies

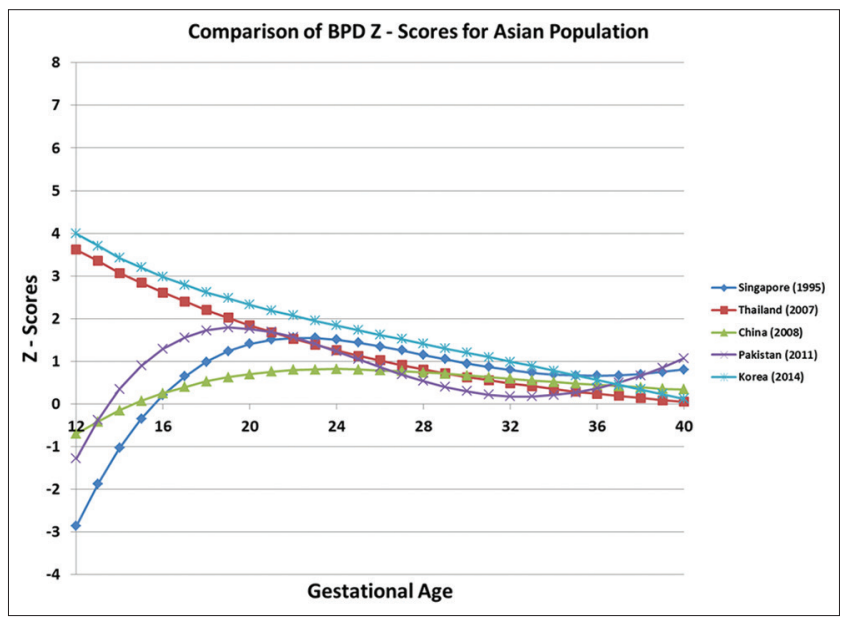

Fig. 5: Z score comparison with Asian studies

Table 3: BPD parameters of the present study compared with other Indian studies

\begin{tabular}{|c|c|c|c|c|c|c|c|c|c|}
\hline GA & $\begin{array}{l}\text { Chennai } \\
(2003)[16]\end{array}$ & $\begin{array}{l}\text { Gujarat } \\
(2009)[17]\end{array}$ & $\begin{array}{l}\text { Pune } \\
(2010)[18]\end{array}$ & $\begin{array}{l}\text { Present } \\
\text { study }\end{array}$ & GA & $\begin{array}{l}\text { Chennai } \\
(2003)[16]\end{array}$ & $\begin{array}{l}\text { Gujarat } \\
(2009)[17]\end{array}$ & $\begin{array}{l}\text { Pune } \\
(2010)[18]\end{array}$ & $\begin{array}{l}\text { Present } \\
\text { study }\end{array}$ \\
\hline 12 & 20.3 & 20.8 & 22.6 & 20.4 & 27 & 67.8 & 68.1 & 65.4 & 67.1 \\
\hline 13 & 23.2 & 23.7 & 25.2 & 23.4 & 28 & 70.7 & 70.9 & 68.1 & 69.9 \\
\hline 14 & 26.2 & 26.7 & 28 & 26.5 & 29 & 73.6 & 73.7 & 70.7 & 72.6 \\
\hline 15 & 29.2 & 29.8 & 30.7 & 29.6 & 30 & 76.2 & 76.3 & 73.2 & 75.2 \\
\hline 16 & 32.4 & 32.9 & 33.6 & 32.8 & 31 & 78.8 & 78.7 & 75.7 & 77.7 \\
\hline 17 & 35.6 & 36.1 & 36.4 & 35.9 & 32 & 81.2 & 81 & 78 & 80 \\
\hline 19 & 42.1 & 42.6 & 42.3 & 42.4 & 34 & 85.5 & 85.1 & 82.3 & 84.2 \\
\hline 20 & 45.4 & 45.9 & 45.2 & 45.6 & 35 & 87.3 & 86.8 & 84.3 & 86.1 \\
\hline 21 & 48.7 & 49.2 & 48.2 & 48.8 & 36 & 88.9 & 88.3 & 86.2 & 87.8 \\
\hline 22 & 52 & 52.5 & 51.1 & 52 & 37 & 90.3 & 89.6 & 87.8 & 89.3 \\
\hline 23 & 55.3 & 55.7 & 54 & 55.1 & 38 & 91.5 & 90.6 & 89.3 & 90.6 \\
\hline 24 & 58.5 & 58.9 & 56.9 & 58.2 & 39 & 92.4 & 91.4 & 90.7 & 91.6 \\
\hline 25 & 61.7 & 62 & 59.8 & 61.2 & 40 & 93 & 91.9 & 91.9 & 92.5 \\
\hline 26 & 64.8 & 65.1 & 62.6 & 64.2 & & & & & \\
\hline
\end{tabular}

BPD: Biparietal diameter, GA: Gestational age 
Table 4: BPD parameters of the present study compared with other Asian studies

\begin{tabular}{|c|c|c|c|c|c|c|}
\hline GA & Singapore (1995) [10] & Thailand (2007) [19] & China (2008) [20] & Pakistan (2011) [21] & Korea (2014) [22] & $\begin{array}{l}\text { Present } \\
\text { Study }\end{array}$ \\
\hline 12 & 17.7 & 23.8 & 19.8 & 19.2 & 24.2 & 20.4 \\
\hline 13 & 21.6 & 26.6 & 23 & 23.1 & 27 & 23.4 \\
\hline 14 & 25.5 & 29.5 & 26.3 & 26.8 & 29.9 & 26.5 \\
\hline 15 & 29.2 & 32.5 & 29.7 & 30.5 & 32.8 & 29.6 \\
\hline 16 & 33 & 35.5 & 33 & 34.1 & 35.9 & 32.8 \\
\hline 17 & 36.6 & 38.5 & 36.4 & 37.6 & 38.9 & 35.9 \\
\hline 19 & 43.8 & 44.7 & 43.1 & 44.4 & 45.2 & 42.4 \\
\hline 20 & 47.2 & 47.7 & 46.4 & 47.6 & 48.3 & 45.6 \\
\hline 21 & 50.6 & 50.8 & 49.7 & 50.8 & 51.4 & 48.8 \\
\hline 22 & 53.9 & 53.9 & 53 & 53.9 & 54.6 & 52 \\
\hline 23 & 57.1 & 56.9 & 56.2 & 56.9 & 57.6 & 55.1 \\
\hline 24 & 60.2 & 59.9 & 59.3 & 59.9 & 60.7 & 58.2 \\
\hline 25 & 63.3 & 62.8 & 62.4 & 62.7 & 63.7 & 61.2 \\
\hline 26 & 66.2 & 65.7 & 65.4 & 65.5 & 66.6 & 64.2 \\
\hline 28 & 71.8 & 71.2 & 71.1 & 70.8 & 72.2 & 69.9 \\
\hline 29 & 74.4 & 73.8 & 73.8 & 73.3 & 74.8 & 72.6 \\
\hline 30 & 76.9 & 76.3 & 76.4 & 75.7 & 77.3 & 75.2 \\
\hline 31 & 79.3 & 78.7 & 78.8 & 78.1 & 79.7 & 77.7 \\
\hline 32 & 81.5 & 80.9 & 81.1 & 80.3 & 81.9 & 80 \\
\hline 33 & 83.7 & 83 & 83.3 & 82.5 & 84 & 82.2 \\
\hline 34 & 85.7 & 85 & 85.3 & 84.6 & 85.9 & 84.2 \\
\hline 35 & 87.6 & 86.7 & 87.2 & 86.7 & 87.6 & 86.1 \\
\hline 36 & 89.3 & 88.3 & 88.8 & 88.6 & 89.1 & 87.8 \\
\hline 37 & 90.9 & 89.7 & 90.3 & 90.5 & 90.4 & 89.3 \\
\hline 38 & 92.4 & 90.9 & 91.6 & 92.3 & 91.4 & 90.6 \\
\hline 39 & 93.7 & 91.9 & 92.6 & 94 & 92.3 & 91.6 \\
\hline 40 & 94.9 & 92.6 & 93.5 & 95.6 & 92.9 & 92.5 \\
\hline
\end{tabular}

Table 5: BPD parameters of the present study compared with non-Asian countries

\begin{tabular}{|c|c|c|c|c|c|c|c|}
\hline GA & France (2006) [23] & Netherlands (2008) [24] & Italy (2009) [25] & USA (2012) [26] & Egypt (2012) [27] & Brazil (2014) [28] & $\begin{array}{l}\text { Present } \\
\text { study }\end{array}$ \\
\hline 12 & 27.8 & 19.3 & 25.2 & 21.6 & 20.9 & 16.2 & 20.4 \\
\hline 13 & 29.7 & 23.1 & 27.7 & 24.4 & 24.3 & 20.4 & 23.4 \\
\hline 14 & 31.7 & 26.8 & 30.4 & 27.4 & 27.7 & 24.6 & 26.5 \\
\hline 15 & 34 & 30.6 & 33.2 & 30.4 & 31.1 & 28.6 & 29.6 \\
\hline 16 & 36.5 & 34.2 & 36.1 & 33.5 & 34.5 & 32.6 & 32.8 \\
\hline 17 & 39.2 & 37.8 & 39.1 & 36.6 & 37.8 & 36.4 & 35.9 \\
\hline 19 & 44.8 & 44.9 & 45.2 & 43 & 44.4 & 43.8 & 42.4 \\
\hline 20 & 47.8 & 48.4 & 48.4 & 46.2 & 47.6 & 47.3 & 45.6 \\
\hline 21 & 50.8 & 51.8 & 51.6 & 49.4 & 50.8 & 50.7 & 48.8 \\
\hline 22 & 53.9 & 55.1 & 54.8 & 52.6 & 53.9 & 54 & 52 \\
\hline 23 & 57.1 & 58.4 & 58 & 55.8 & 56.9 & 57.2 & 55.1 \\
\hline 24 & 60.2 & 61.6 & 61.1 & 58.9 & 59.9 & 60.3 & 58.2 \\
\hline 25 & 63.3 & 64.7 & 64.2 & 62 & 62.8 & 63.3 & 61.2 \\
\hline 26 & 66.4 & 67.8 & 67.3 & 65 & 65.6 & 66.1 & 64.2 \\
\hline 29 & 75.2 & 76.5 & 75.8 & 73.5 & 73.6 & 74.1 & 72.6 \\
\hline 30 & 77.9 & 79.2 & 78.4 & 76.2 & 76.1 & 76.6 & 75.2 \\
\hline 31 & 80.4 & 81.8 & 80.9 & 78.7 & 78.5 & 78.9 & 77.7 \\
\hline 32 & 82.8 & 84.4 & 83.1 & 81 & 80.7 & 81.2 & 80 \\
\hline 33 & 85 & 86.8 & 85.2 & 83.2 & 82.9 & 83.3 & 82.2 \\
\hline 34 & 86.9 & 89.2 & 87.1 & 85.3 & 84.9 & 85.4 & 84.2 \\
\hline 35 & 88.7 & 91.4 & 88.8 & 87.1 & 86.8 & 87.3 & 86.1 \\
\hline 36 & 90.1 & 93.5 & 90.2 & 88.8 & 88.6 & 89.1 & 87.8 \\
\hline 37 & 91.3 & 95.6 & 91.4 & 90.3 & 90.2 & 90.8 & 89.3 \\
\hline 38 & 92.2 & 97.5 & 92.3 & 91.5 & 91.7 & 92.4 & 90.6 \\
\hline 39 & 92.7 & 99.3 & 92.9 & 92.5 & 93.1 & 93.9 & 91.6 \\
\hline 40 & 92.9 & 101 & 93.2 & 93.3 & 94.3 & 95.3 & 92.5 \\
\hline
\end{tabular}

BPD: Biparietal diameter, GA: Gestational age 


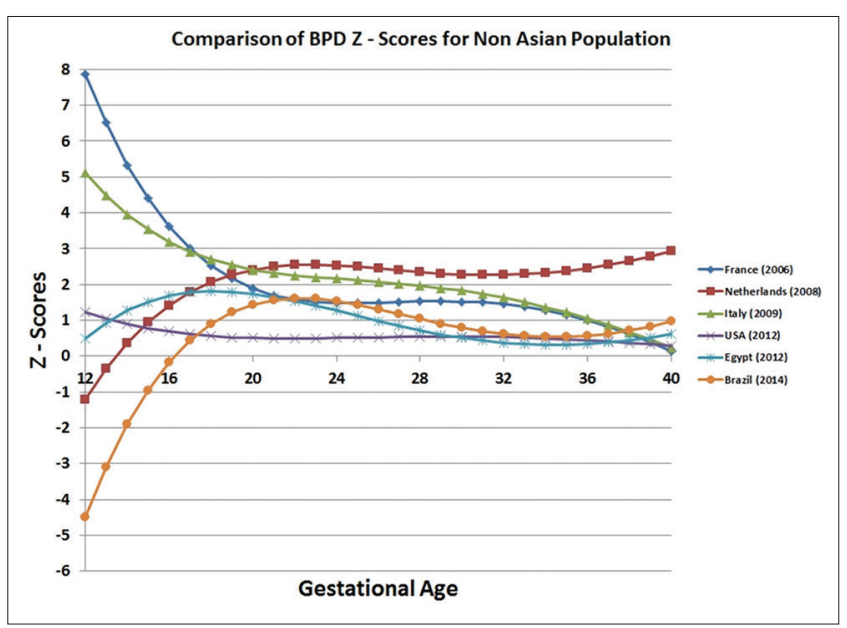

Fig. 6: Z score comparison with non-Asian studies

age of the fetus can be determined. BPD is easier to obtain and it can be a useful tool at term for the purpose of ultrasound cephalometry. It is recommended that each local population should have its own nomograms of BPD so that there is no need to refer to other charts and errors in GA estimation can be thus minimized.

\section{CONFLICT OF INTEREST}

None.

\section{AUTHOR'S CONTRIBUTION}

Shripad Hebbar: Data analysis and draft preparation, Tracy Khuraijam: Data collection and compilation.

\section{REFERENCES}

1. Campbell $\mathrm{S}$. The prediction of fetal maturity by ultrasonic measurement of the biparietal diameter. J Obstet Gynaecol $\mathrm{Br}$ Commonw 1969;76:603-9.

2. Ugwu EO, Odoh GU, Dim CC, Obi SN, Ezugwu EC, Okafor II, et al. Women's perception of accuracy of ultrasound dating in late pregnancy: A challenge to prevention of prolonged pregnancy in a resource-poor Nigerian setting. Int J Womens Health 2014;6:195-200.

3. Hadlock FP, Deter RL, Harrist RB, Park SK. Fetal head biparietal diameter: A critical reevaluation to menstrual age by means of real time ultrasound. J Ultrasound Med 1982;1:97-104

4. Bacak SJ, Olson-Chen C, Pressman E. Timing of induction of labor. Semin Perinatol 2015;39:450-8.

5. Chervenak FA, Jeanty P, Cantraine F, Chitkara U, Venus I, Berkowitz RL, et al. The diagnosis of fetal microcephaly. Am J Obstet Gynecol 1984;149:512-7.

6. Hohler CW, Lea J, Collins H. Screening for intrauterine growth retardation using the ultrasound biparietal diameter. J Clin Ultrasound 1976;4:187-91.

7. Jaiswal P, Masih WF, Jaiswal S, Chowdhary DS. Assessment of fetal gestational age by ultrasonic measurement of bi-parietal diameter in the southern part of Rajasthan. Med J DY Patil Univ 2015;8:27-30.

8. Shepard M, Filly RA. A standardized plane for biparietal diameter measurement. J Ultrasound Med 1982;1:145-50.

9. Hebbar S, Khuraijam T. An experimental design to obtain nonlinear model for fitting intrauterine growth curve using Microsoft Excel spread sheet program. Int J Med Health Res 2016;2:1-4.

10. Lai FM, Yeo GS. Reference charts of foetal biometry in Asians. Singapore Med J 1995;36:628-36.

11. Donald I, Abdulla U. Further advances in ultrasonic diagnosis. Ultrasonics 1967;5:8-12.

12. Campbell S. An improved method of fetal cephalometry by ultrasound. J Obstet Gynaecol Br Commonw 1968;75:568-76.

13. Griffith JM, Henry WL. A sector scanner for real time two-dimensional echocardiography. Circulation 1974;49:1147-52.

14. Varma TR. Prediction of delivery date by ultrasound cephalometery. $\mathrm{Br}$ J Obstet Gynaecol 1978;80:316.

15. Beigi A, ZarrinKoub F. Ultrasound assessment of fetal biparietal diameter and femur length during normal pregnancy in Iranian women. Int J Gynaecol Obstet 2000;69:237-42.

16. Suresh S, Thangavel G. Mathemetical modeling of fetal growth, Part I: Data collection and descrtiptive statistics. Internet J Med Update 2003;3:35-41

17. Acharya P, Acharya A. Evaluation of applicability of standard growth curves to Indian women by fetal biometry. South Asian Fed Obstet Gynaecol 2009;3:55-61.

18. Kinare AS, Chinchwadkar MC, Natekar AS, Coyaji KJ, Wills AK, Joglekar CV, et al. Patterns of fetal growth in a rural Indian cohort and comparison with a western European population: Data from the pune maternal nutrition study. J Ultrasound Med 2010;29:215-23.

19. Saksiriwuttho P, Ratanasiri T, Komwilaisak R. Fetal biometry charts for normal pregnant women in North Eastern Thailand. J Med Assoc Thai 2007;90:1963-9.

20. Leung TN, Pang MW, Daljit SS, Leung TY, Poon CF, Wong SM, et al. Fetal biometry in ethnic Chinese: Biparietal diameter, head circumference, abdominal circumference and femur length. Ultrasound Obstet Gynecol 2008:31:321-7.

21. Akhtar W, Ali A, Arain MA, Saeed F, Siddiqui S, Memon A, et al. Sonographic fetal biometry charts for a Pakistani cohort. East Mediterr Health J 2011:17:969-75.

22. Kwon JY, Park IY, Wie JH, Choe S, Kim CJ, Shin JC, et al. Fetal biometry in the Korean population: Reference charts and comparison with charts from other populations. Prenat Diagn 2014;34:927-34.

23. Salomon LJ, Duyme M, Crequat J, Brodaty G, Talmant C, Fries N, et al. French fetal biometry: Reference equations and comparison with other charts. Ultrasound Obstet Gynecol 2006;28:193-8.

24. Verburg BO, Steegers EA, De Ridder M, Snijders RJ, Smith E, Hofman A, et al. New charts for ultrasound dating of pregnancy and assessment of fetal growth: Longitudinal data from a population-based cohort study. Ultrasound Obstet Gynecol 2008;31:388-96.

25. Giorlandino M, Padula F, Cignini P, Mastrandrea M, Vigna R, Buscicchio $\mathrm{G}$, et al. Reference interval for fetal biometry in Italian population. J Prenat Med 2009;3:62-5.

26. Briceño F, Restrepo H, Paredes R, Cifuentes R. Fetal size charts for a population from Cali, Colombia: Sonographic measurements of biparietal diameter, head circumference, abdominal circumference, and femur length. J Ultrasound Med 2013;32:1215-25.

27. Morsy MM, El Ashtokhy MA, Diab AE, Mansoor MA. Different measurements of ultrasonic biometry of the egyptian fetuses. Zagazig Univ Med J 2012;18:861-73.

28. Araujo Júnior E, Martins Santana EF, Martins WP, Júnior JE, Ruano R, Pires CR, et al. Reference charts of fetal biometric parameters in 31,476 Brazilian singleton pregnancies. J Ultrasound Med 2014;33:1185-91.

29. Yeomans ER. Clinical pelvimetry. Clin Obstet Gynecol 2006;49:140-6.

30. Pattinson RC, Cuthbert A, Vannevel V. Pelvimetry for fetal cephalic presentations at or near term for deciding on mode of delivery. Cochrane Database Syst Rev 2017;3:CD000161.

31. Venkateswaramurthy N, John C, Perumal P. Study on antihypertensives in preeclampsia. Asian J Pharm Clin Res 2012:5:126-8

32. Hebbar S, Kumar S, Amin S, Doizode S. Subclinical hypothyroidism in pregnancy; is there a need for pharmacological intervention? Int J Pharm Pharm Sci 2017;9:186-91 